\title{
Drug Shortages: More than Just Background Noise
}

\author{
Susan K Bowles
}

$\mathrm{T}$ he Canadian Journal of Hospital Pharmacy (CJHP) first published an editorial regarding drug shortages in $2012 .{ }^{1}$ Almost 7 years later, this issue of CJHP includes a study comparing several aspects of drug shortages among Canada and 4 European countries, serving to remind us that the drug shortage problem is far from resolved. Videau and others ${ }^{2}$ found that across all 5 study sites, drug shortages occurred on a daily basis, predominantly affecting injectable products. Furthermore, shortages could be prolonged: in the Canadian study hospital, the median duration was 32 days, but shortages could last longer than a year, with the longest reported shortage being 402 days. $^{2}$ These data are consistent with those reported by Drug Shortages Canada, which currently (as of early 2018) estimates about 300 shortages, affecting vaccines, chemotherapeutic agents, antibiotics, and other drugs commonly used in the hospital setting. ${ }^{3}$ Indeed, drug shortages have become so commonplace that some pharmacists have come to consider this issue as the "background noise" of today's hospital pharmacy practice (Stephen Shalansky, Providence Healthcare, Lower Mainland Pharmacy Services; personal communication, November 8, 2018).

Drug shortages can arise at multiple points throughout the supply chain. For example, there may be shortages or contamination of raw materials or active ingredients, manufacturing issues related to quality control, production delays, and contracting issues such as reliance on a single supplier. ${ }^{4}$ Pharmacy departments do their best to alleviate the impact of this common problem, but there is no doubt that despite these efforts, drug shortages have the potential to negatively affect patient care.

First, drug shortages can directly affect patient outcomes. For example, shortages of chemotherapeutic agents can delay treatment, lead to use of reduced doses, or require substitution of therapies not supported by evidence, potentially affecting survival rates. ${ }^{5}$ Likewise, shortages of anesthesia medications have been reported to delay surgery or necessitate substitution of agents associated with prolonged recovery time or protracted postoperative nausea and vomiting, potentially resulting in increased length of stay and poorer overall surgical outcomes. ${ }^{6}$ Shortages of norepinephrine in US hospitals have been associated with increased mortality among patients with septic shock. ${ }^{7}$ The Institute for Safe Medication Practices (US) reported 1 death that was partially attributed to a delay in treating sepsis-related acidosis with sodium bicarbonate during a recent shortage. ${ }^{8}$

Second, the use of unfamiliar medications or different strengths, concentrations, and formulations, which may occur during a shortage, increases the risk of medication error. ${ }^{9}$ Areas of particular risk have been outlined by the Institute for Safe Medication Practices Canada (ISMP Canada). ${ }^{9}$ For example, use of alternative drugs, concentrations, strengths, or dosage forms introduces potential for error across the medication-use system in the prescribing, preparation, administration, and/or monitoring processes. ${ }^{9}$ Furthermore, these alternative therapies may not be included in the hospital's usual resources, such as order sets, parenteral drug therapy manuals, or smart pump libraries. ${ }^{9}$ Two surveys of US health care personnel highlighted this risk. Among 300 health care personnel responding to the 2017 survey, of whom about two-thirds were pharmacists, at least 1 error was reported by $21 \%$ of respondents, and among the errors reported, several involved high-risk medications, such as opioids, potassium chloride, and epinephrine. ${ }^{8}$ In the earlier survey, conducted in 2010, at least 1 near miss was reported by 35\% of the 1800 respondents. ${ }^{10}$ ISMP Canada has reported 1 incident related to a shortage of topical epinephrine in which parenteral epinephrine 1:1000 was substituted for a local anesthetic; the incorrect drug was drawn up into an unlabelled syringe, then administered by injection into the operative site, resulting in cardiac arrest and death. ${ }^{11}$

Third, drug shortages also have indirect effects on patient safety. In the same US survey referenced above, ${ }^{8}$ more than one-third of respondents provided comments about the human and financial resources required to manage drug shortages. In particular, they noted that time spent managing drug shortages 
diverted them from time usually spent on patient care and medication safety activities, which resulted in greater risk for error. ${ }^{8}$ This increased risk of error may be due, in part, to the effect that drug shortages can have on workload, fatigue, and mental distraction for front-line staff.' Pharmacists and pharmacy technicians also reported that other health care professionals frequently express their frustration with drug shortages directly to pharmacy staff, which leads to poor morale and further increases the risk for error. ${ }^{8}$

Drug shortages pose a risk to patients for many reasons. Pharmacists and pharmacy technicians should be proud of the work they do every day to mitigate that risk. That only a few serious negative patient outcomes have been reported attests to the importance of pharmacy staff on the front line of patient safety. Yet it is easy to lose focus when faced with an ongoing problem that requires our continuous vigilance. Given the potential for patient harm, drug shortages are clearly more than just background noise. We need to remember that and work toward more permanent solutions to the drug shortage problem.

\section{References}

1. Vaillancourt R. Drug shortages: what can hospital pharmacists do? [editorial]. Can J Hosp Pharm. 2012;65(3):175-6.

2. Videau M, Chemali L, Stucki C, Saavedra-Mitjans M, Largana S, Guerin A, et al. Drug shortages in Canada and selected European countries: a crosssectional, institution-level comparison. Can J Hosp Pharm. 2019;72(1):7-15.

3. Drug shortages homepage [website]. Ottawa (ON): Drug Shortages Canada; [cited 2018 Nov 13]. Available from: https://www.drugshortagescanada.ca/

4. Rinaldi F, de Denus S, Nguyen A, Nattel S, Bussières JF. Drug shortages: patients and health care providers are all drawing the short straw. Can J Cardiol. 2017;33(2):283-6.

5. McBride A, Holle LM, Westendorf C, Sidebottom M, Griffith N, Muller RJ, et al. National survey of drug shortages on cancer care. Am J Health Syst Pharm. 2013;70(7):609-17.

6. Hall R, Bryson GL, Flowerdew G, Neilpovitz D, Grabowski-Comeau, Turgeon AF; Canadian Perioperative Anesthesia Clinical Trials Group. Drug shortages in Canadian anesthesia: a national survey. Can J Anesth. 2013;60(6):539-51.
7. Vail E, Gershengorn HB, Hua M, Walkey AJ, Rubenfeld G, Wunsch H. Association between US norepinephrine shortage and mortality among patients with septic shock. JAMA. 2017;317(14):1433-42.

8. Drug shortages continue to compromise patient care. Horsham (PA): Institute for Safe Medication Practices; 2018 [cited 2019 Jan 9]. Available from: https://www.ismp.org/resources/drug-shortages-continue-compromisepatient-care

9. Drug shortages and medication safety concerns. ISMP Can Saf Bull. 2012 [cited 2019 Jan 7];12(3):1-4. Available from: https://www. ismp-canada.org/download/safetyBulletins/2012/ISMPCSB2012-03_ Drug_Shortages.pdf

10. Special issue: Drug shortages: national survey reveals high level of frustration, low level of safety. Horsham (PA): Institute for Safe Medication Practices; 2010 [cited 2019 Jan 23]. Available from: https://www.ismp.org/resources/specialissue-drug-shortages-national-survey-reveals-high-level-frustration-low-level

11. Alert: shortage of topical epinephrine 1:1000 poses safety risks. ISMP Can Saf Bull. 2015 [cited 2019 Jan 13];15(3):1-2. Available from: https://www.ismp-canada.org/download/safetyBulletins/2015/ISMPCSB2015 -03_ShortageTopicalEpinephrine.pdf

Susan K Bowles, PharmD, MSc, is with the Pharmacy, Nova Scotia Health Authority, and the College of Pharmacy, Dalhousie University, Halifax, Nova Scotia. She is also an Associate Editor with the Canadian Journal of Hospital Pharmacy.

Competing interests: None declared.

Address correspondence to:

Dr Susan K Bowles

Pharmacy

Nova Scotia Health Authority

1796 Summer Street

Halifax NS B3H 3 A7

e-mail: susan.bowles@nshealth.ca 